\title{
An interesting case of intrauterine torsion of ovarian cyst in a female fetus
}

\author{
Jaya Barla, Vaishali K. Nayak*, Kalpesh Patil
}

Department of Obstetrics and Gynecology, MIMER Medical College, Talegaon Dabhade, Pune, Maharashtra, India

Received: 28 December 2020

Accepted: 04 February 2021

\section{*Correspondence:}

Dr. Vaishali K. Nayak,

E-mail: drvaishalinayak@gmail.com

Copyright: () the author(s), publisher and licensee Medip Academy. This is an open-access article distributed under the terms of the Creative Commons Attribution Non-Commercial License, which permits unrestricted non-commercial use, distribution, and reproduction in any medium, provided the original work is properly cited.

\section{ABSTRACT}

Fetal ovarian cysts are usually benign and managed conservatively. We report an interesting case of fetal ovarian cyst diagnosed in the antenatal period. Post-delivery, neonate was operated for torsion of the ovarian cyst. The baby recovered well.

Keywords: Fetal abdominal masses, Torsion of ovarian cyst, Intrauterine aspiration

\section{INTRODUCTION}

Advanced technology in ultrasonography has made it possible for diagnosing intrauterine fetal abdominal masses. The most common cause of abdominal mass in a female fetus is ovarian cysts. ${ }^{1}$ Ovarian cysts are the most common abdominal masses in the female fetus with a reported incidence of one in 2500-2625 pregnancies/live births. ${ }^{2,3}$ The incidence of torsion in fetal ovarian cyst with size more than $5 \mathrm{~cm}$ is $31 \% .^{4}$ Due to the advent of good resolution of ultrasonography, high proportion of small ovarian cysts of size $<5 \mathrm{~cm}$ are also diagnosed. Stimulation of fetal ovary by placental and maternal hormones is considered to be responsible for these ovarian cysts, as most of them turn out to be functional and theca lutein cysts histologically. ${ }^{5}$ When the effect of maternal hormone declines, most of the ovarian cysts diagnosed in the antenatal period resolve spontaneously. However, in a few cases, where the mass is large, it may need intervention. We hereby report an interesting case where the antenatal ultrasonography revealed an ovarian cyst which transformed into a haemorrhagic cyst because of intrauterine torsion.

\section{CASE REPORT}

A 26-years-old G3P1L1A1 with 36 weeks gestation was admitted with complains of pain abdomen. Vitals were stable and conservative management was planned. A routine ultrasonography was done for the assessment of fetal wellbeing. Incidentally, the ultrasound showed, single intrauterine fetus with an abdominopelvic mass of size $5 \times 5 \mathrm{~cm}$. The findings were suggestive of right ovarian dermoid cyst/complex ovarian cyst. Paediatric surgeon's opinion was sought and decision to review after birth, was taken. We allowed the patient to go into spontaneous labour and she had a vaginal delivery of a female child with a birth weight of $2.8 \mathrm{~kg}$. Baby cried immediately after birth with a good Apgar score. The vitals were stable and no other pathology was detected apart from a soft palpable mass in the right lower quadrant. Baby was shifted to neonatal intensive care unit (NICU) for observation.

Postnatal computed tomography (CT) scan showed a large right complex ovarian mass of size $5 \times 4.8 \mathrm{~cm}$. The routine blood investigations were normal; however, tumour marker CA 19-9 was slightly elevated at $42.43 \mathrm{U} / \mathrm{ml}$ (normal range 0-37). The paediatric surgeon reviewed the case and in view of a large complex ovarian cyst causing mass effect on adjacent organs, an exploratory laparotomy were planned. The neonate was taken for laparotomy on postdelivery day 5. An incision was given just above the mass and layers of abdominal wall separated carefully. On inspection, a $5 \times 5 \mathrm{~cm}$ right sided adnexal mass with torsion, 
was found. On delivering the mass, it was realised that it is the left ovary which had come on the right side with the long pedicle undergoing torsion.

Due to the torsion, the entire ovary had become oedematous and normal ovarian tissue could not be found. The left fallopian tube was also adherent to the mass. As the left ovary appeared unsalvageable, decision for salpingo-oophorectomy was taken. Left sided ovary with cyst was removed and sent for histopathology. The right sided ovary was apparently normal. The baby was kept under observation. Post-operative period was uneventful and baby was discharged on $7^{\text {th }}$ post-operative day. The histopathology of the cyst was confirmatory of a congenital haemorrhagic ovarian cyst with calcification with few primordial follicles.

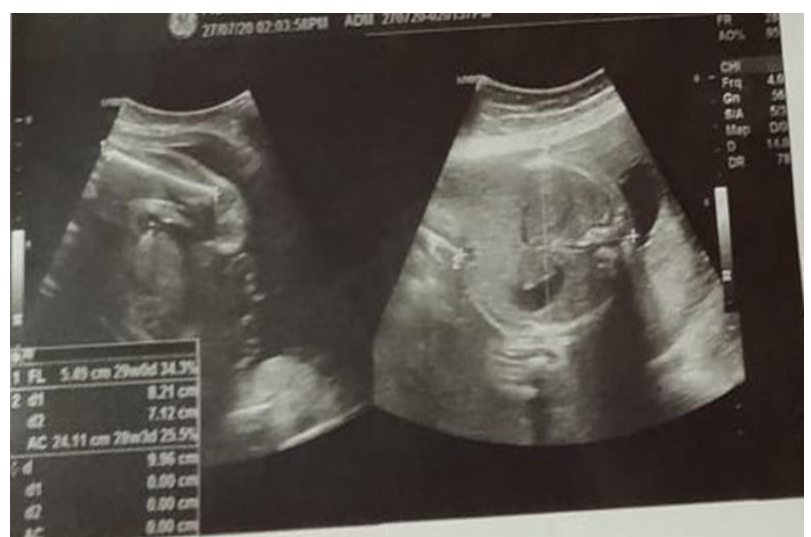

Figure 1: Antenatal ultrasonography.

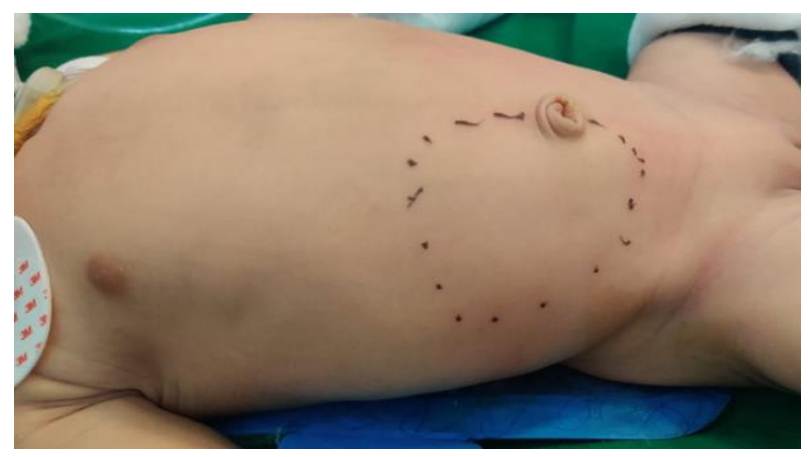

Figure 2: Pre-operative marking of the lump.

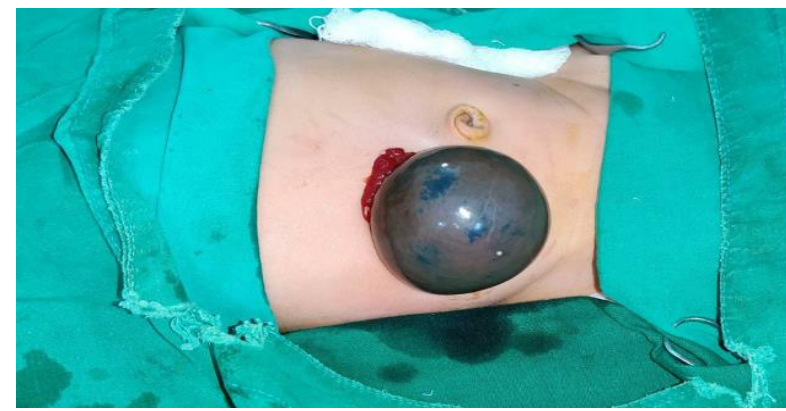

Figure 3: Intraoperative findings of haemorrhagic cyst.

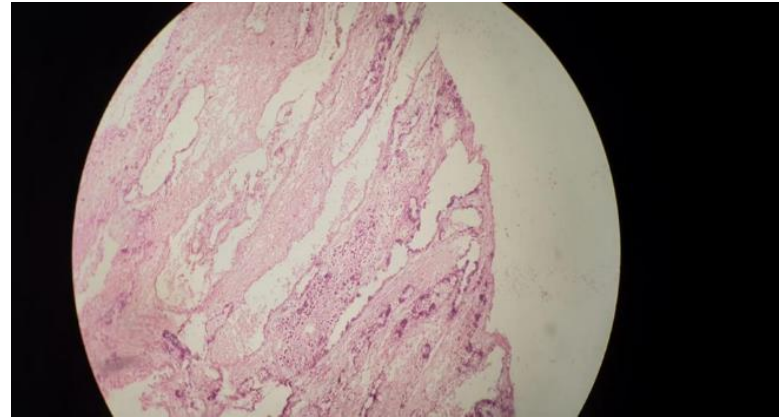

Figure 4: Histopathology of ovarian cyst.

\section{DISCUSSION}

When a cystic abdominal mass is diagnosed in the female fetus, differential diagnosis should be established for mesenteric, omental and urachal cysts, intestinal duplication anomalies, cystic teratoma, and intestinal obstruction, renal cysts, cystic meconium peritonitis, and duodenal atresia. ${ }^{6-8}$

Rare cases of anterior meningocele, lymphangiomas and benign cystic teratoma may also be considered. ${ }^{9}$

It is difficult to differentiate between these conditions and ovarian cysts in the intrauterine period. A CT-scan or MRI may help to establish the exact site of the mass.

Fetal ovarian cysts are commonly diagnosed on ultrasonography. Most of these cysts regress spontaneously without any complications. However, in utero torsion of the ovary, is a rare complication. There are no clear guidelines to manage in-utero ovarian cyst. There are also studies which recommend conservative management of the neonatal ovarian cyst. ${ }^{10,11}$

Study by Kwak et al showed that ovarian cysts diagnosed during pregnancy could be managed conservatively if the size is less than $5 \mathrm{~cm}$. If the size is more, then these patients may need surgical intervention. ${ }^{11}$ There are studies also which recommend aspiration of cysts in the neonatal period. ${ }^{12}$

Considering the low morbidity associated with intrauterine aspiration (IUA) of the ovarian cysts and the reduced rate of oophorectomy among the neonates in the IUA group, systematic IUA might well be worthwhile. ${ }^{12}$ However, one cannot completely rule out neoplastic tumours, hence aspiration needs further systematic trials.

Torsion of the ovarian cyst, as seen in our case, is not frequently encountered. MRI may detect torsion of the ovary in-utero in female fetus. There are no clear guidelines on how to manage in-utero torsion of the ovary. There are varied opinions as regard to management of such cases. There are some opinions that the fetus should be delivered early so that ovary may be saved. The other line of thought is that, one cannot be sure as for how long the 
torsion has been there, so it is difficult to save the ovary anyways, so there is no point of early delivery. ${ }^{13}$

A meta-analysis showed that ovarian cysts of size $<3 \mathrm{~cm}$, diagnosed prenatally, regressed spontaneously. In a metaanalysis examining the prognosis of ovarian cysts, it was reported that of 346 prenatally diagnosed ovarian cysts, $10 \%$ were spontaneously resorbed in the prenatal period and $36 \%$ in the postnatal period, for a total of $46 \%$ spontaneous resorption. ${ }^{14}$

Ovarian cysts should be followed up in the postnatal period at 4 to 6 weeks interval with serial ultrasonography until they are resorbed or symptomatic. Surgical removal is recommended for complex cysts, ovarian torsion, symptomatic patients, and cysts that do not regress in size by the sixth month. Our patient underwent surgery on postnatal day 5 in view of a large mass with torsion, which had occurred in the intrauterine period.

\section{CONCLUSION}

In conclusion, in-utero torsion of the ovary is rare diagnosis. It is difficult to diagnose such cases in the prenatal period. In case of torsion of the ovary, it is difficult to save the ovary and patient may need oophorectomy. There is a doubt about subfertility in these patients in future. Further trials are needed to form guidelines to form guidelines for the management of fetal ovarian cysts.

\section{ACKNOWLEDGMENTS}

We are thankful to the department of paediatrics and anaesthesiology of MIMER Medial College, for taking care of the patient in the post-operative period and during this high-risk surgery.

Funding: No funding sources Conflict of interest: None declared

Ethical approval: Not required

\section{REFERENCES}

1. Crombleholme TM, Craigo SD, Garmel S, Alton ME. Fetal ovarian cyst decompression to prevent torsion. J Pediatr Surg. 1997;32(10):1447-9.

2. Enriquez G, Duran C, Toran N, Piqueras J, Gratacos $\mathrm{E}$, Aso C, et al. Conservative versus surgical treatment for complex neonatal ovarian cysts: outcomes study. AJR Am J Roentgenol. 2005;185(2):501-8.
3. Papic JC, Billmire DF, Rescorla FJ, Finnell SM, Leys CM. Management of neonatal ovarian cysts and its effect on ovarian preservation. J Pediatr Surg. 2014;49(6):990-3.

4. Bagolan P, Giorlandino C, Nahom A, Bilancioni E, Trucchi A, Gatti C, et al. The management of fetal ovarian cysts. J Pediatr Surg. 2002;37:25-30.

5. Perrotin F, Potin J, Haddad G, Sembely TC, Lansac J, Body G. Fetal ovarian cysts: a report of three cases managed by intrauterine aspiration. Ultrasound Obstet Gynecol. 2000;16(7):655-9.

6. Gauderer MW, Jassani MN, Izant RJ. Ultrasonographic antenatal diagnosis: will it change the spectrum of neonatal surgery?. J Pediatr Surg. 1984;19(4):404-7.

7. Sandler MA, Smith SJ, Pope SG, Madrazo BL. Prenatal diagnosis of septated ovarian cysts. J Clin Ultrasound. 1985;13(1):55-7.

8. Nussbaum AR, Sanders RC, Benator RM, Haller JA, Dudgeon DL. Spontaneous resolution of neonatal ovarian cysts. AJR Am J Roentgenol. 1987;148(1):175-6.

9. Vogtlander MF, Rijntjes JEG, Hoonaard TL, Versteegh FG. Neonatal ovarian cysts. Acta Paediatr. 2003;92(4):498-501.

10. Akın MA, Akın L, Ozbek S, Tireli G, Kavuncuoglu S, Sander S, Akçakuş M, et al. Fetal-neonatal ovarian cysts--their monitoring and management: retrospective evaluation of 20 cases and review of the literature. J Clin Res Pediatr Endocrinol. 2010;2(1):28-33

11. Kwak DW, Sohn YS, Kim SK, Kim IK, Park YW, Kim YH. Clinical experiences of fetal ovarian cyst: diagnosis and consequence. J Korean Med Sci. 2006;21(4):690-4.

12. Diguisto C, Winer N, Benoist G, Laurichesse DH, Potin J, Binet A, et al. In-utero aspiration vs expectant management of anechoic fetal ovarian cysts: open randomized controlled trial. Ultrasound Obstet Gynecol. 2018;52(2):159-64.

13. Saeed H, Hong L, Smith N, Shaman M. Ovarian torsion in utero diagnosed at 37 weeks of pregnancy: A case report. Case Rep Womens Health. 2020;27:232.

14. Tyraskis A, Bakalis S, David AL, Eaton S, Coppi P. A systematic review and meta-analysis on fetal ovarian cysts: impact of size, appearance and prenatal aspiration. Prenat Diagn. 2017;37(10):951-8.

Cite this article as: Barla J, Nayak VK, Patil K. An interesting case of intrauterine torsion of ovarian cyst in a female foetus. Int J Reprod Contracept Obstet Gynecol 2021;10:3223-5. 